97-2017

Atti di convegno internazionale con peer review

Bollini, L. (2017). Drawing as a learning enabling meta-language. Using sketch noting in the field of education. In L. Gómez Chova, A. López Martínez, I. Candel Torres (Eds.) ICERI2017 Proceedings (pp. 8030-8036). IATED Academy: Seville

[ISBN: 978-84-697-6957-7; ISSN: 2340-1095] 

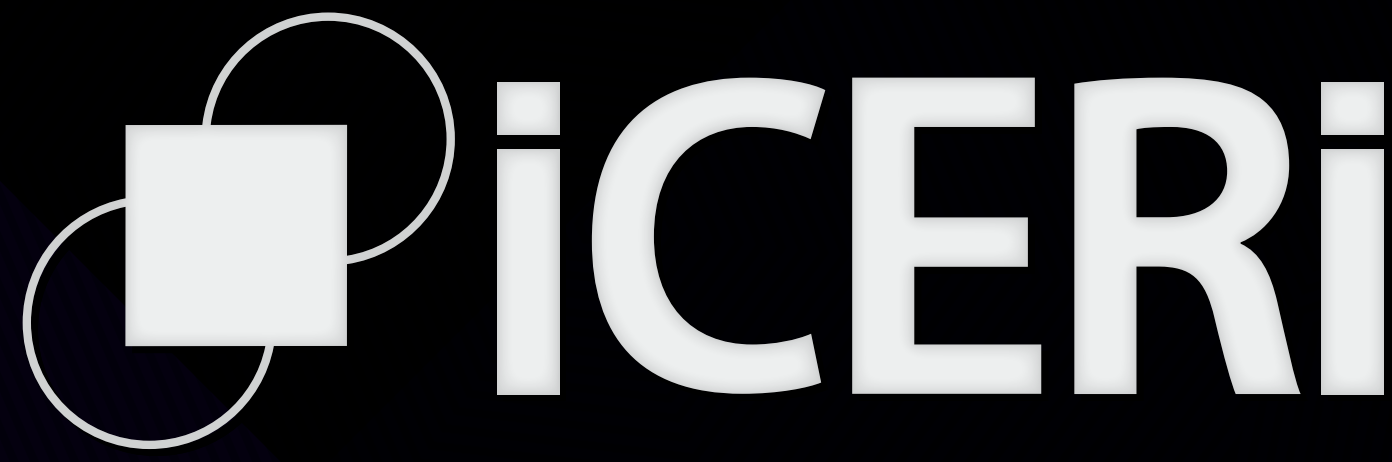

2017

10TH INTERNATIONAL CONFERENCE OF EDUCATION,

RESEARCH AND

INNOVATION
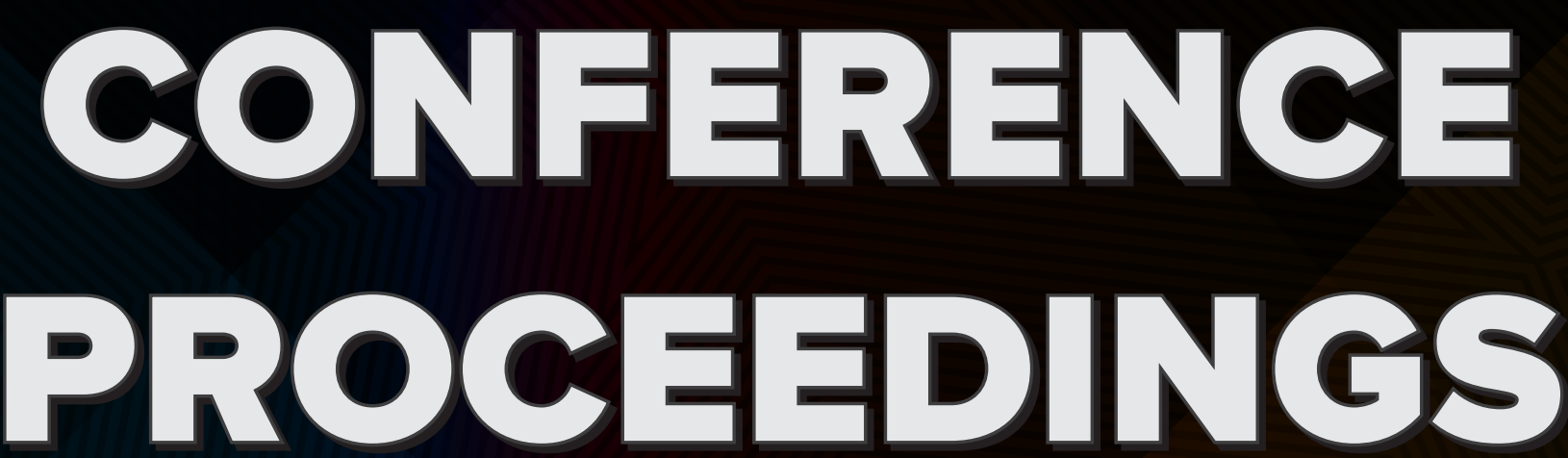

SEVILLE (SPAIN)

16-18 NOVEMBER 2017 

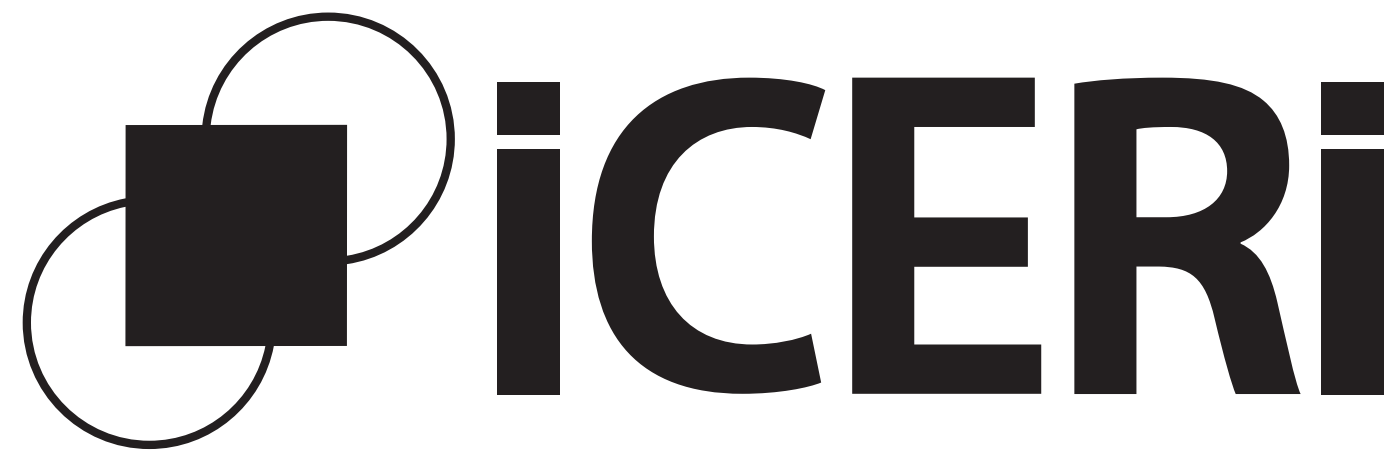

2017

IOTH INTERNATIONAL CONFERENCE OF EDUCATION,

RESEARCH AND

INNOVATION
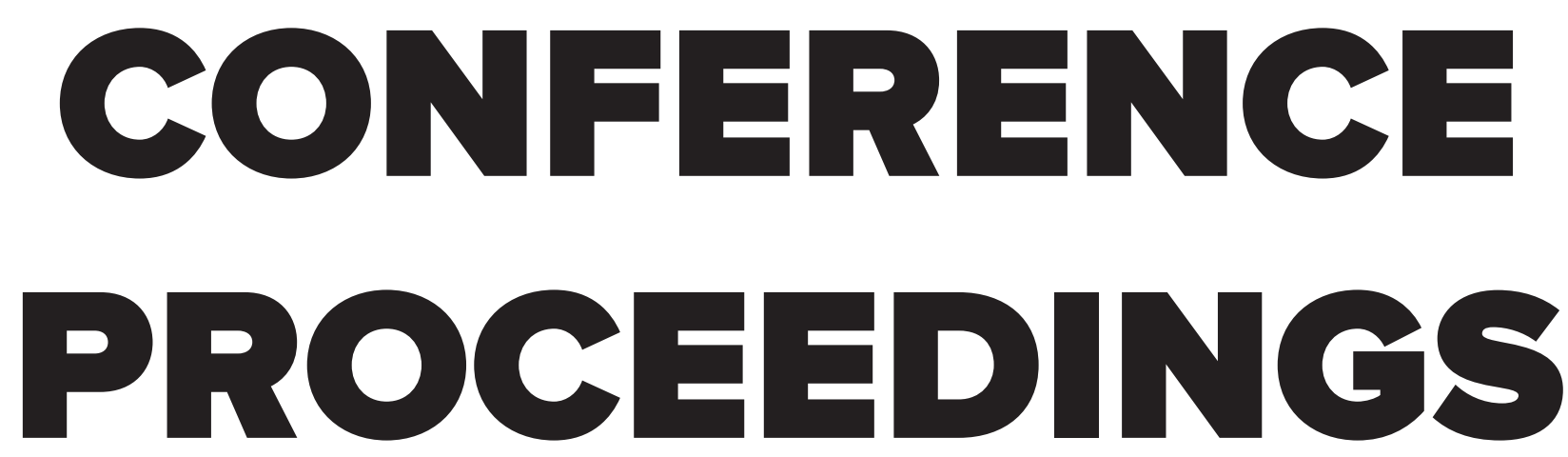

SEVILLE (SPAIN) 16-18 NOVEMBER 2017 
Published by

IATED Academy

iated.org

\section{ICERI2017 Proceedings}

10th International Conference of Education, Research and Innovation

November 16th-18th, 2017 - Seville, Spain

\section{Edited by}

L. Gómez Chova, A. López Martínez, I. Candel Torres

IATED Academy

ISBN: 978-84-697-6957-7

ISSN: 2340-1095

Depósito Legal: V- 2851-2017

Book cover designed by

J.L. Bernat

All rights reserved. Copyright (C) 2017, IATED

The papers published in these proceedings reflect the views only of the authors. The publisher cannot be held responsible for the validity or use of the information therein contained. 


\section{ICERI2017 COMMITTEE AND ADVISORY BOARD}

\begin{tabular}{|c|}
\hline Aaron Doering \\
\hline Agustín López \\
\hline Alexander Sobolev \\
\hline Ali Merç \\
\hline Amir Dirin \\
\hline Amparo Girós \\
\hline Ana Tomás \\
\hline Angela Piu \\
\hline Anne Omori \\
\hline Antonio García \\
\hline Balamuralithara Balakrishnan \\
\hline Belmiro Gil Cabrito \\
\hline Bernard Etlicher \\
\hline Boris Alexander Becker \\
\hline Bryan Eldridge \\
\hline Carol Ing \\
\hline Chelo González \\
\hline Christos Rodosthenous \\
\hline Cristina Lozano \\
\hline Dana Kubickova \\
\hline David Bolton \\
\hline David Martí \\
\hline David Scaradozzi \\
\hline Deborah Azaryad Shechter \\
\hline Eladio Duque \\
\hline Emmi Pakkala \\
\hline Fumito Yoshikawa \\
\hline Giles Pepler \\
\hline Harvey Oueijan \\
\hline Hen Friman \\
\hline Ignacio Ballester \\
\hline Ignacio Candel \\
\hline Ioana Carmen Paraschiv \\
\hline Ira Raveh \\
\hline Iván Martínez \\
\hline Jana Mazancova \\
\hline Janis Prince \\
\hline Javier Domenech \\
\hline Javier Martí \\
\hline Jean-Paul Becar \\
\hline Joanna Lees \\
\hline Jose F. Cabeza \\
\hline
\end{tabular}

\author{
UNITED STATES Jose Luis Bernat \\ SPAIN Kaye Price \\ RUSSIAN FEDERATION Liliana Milevicich \\ TURKEY Lorena López \\ FINLAND Louis Babineau \\ SPAIN Luis Gómez Chova \\ SPAIN Ma Jesús Suesta \\ ITALY Margus Pedaste \\ NIGERIA Maria Porcel \\ SPAIN Martin Gellerstedt \\ MALAYSIA Melania Tera \\ PORTUGAL Michelle Ellwood \\ FRANCE Minna Maunula \\ GERMANY Mira Alameddine \\ UNITED STATES Nadja Soldatic \\ CANADA Naseer Ahmed \\ SPAIN Nigel Atkinson \\ CYPRUS Norma Barrachina \\ SPAIN Nuraihan Mat Daud \\ CZECH REPUBLIC Olga Teruel \\ UNITED STATES Pablo Opazo \\ SPAIN Pamela Parker \\ ITALY Paulus Insap Santosa \\ ISRAEL Pavel Brebera \\ SPAIN Peter Haber \\ UGANDA Pierre Mora \\ JAPAN Rachel Welton \\ UNITED KINGDOM Rebecca Ferriday \\ LEBANON Rebekka Eckhaus \\ ISRAEL Sergio Pérez \\ SPAIN Sharon Judge \\ SPAIN Svetlana Bekareva \\ ROMANIA Vanja Bevanda \\ ISRAEL Victor Fester \\ SPAIN Wendy Gorton \\ CZECH REPUBLIC William Heintz \\ UNITED STATES William Muirhead \\ SPAIN Willy Castro Guzman \\ SPAIN Xavier Lefranc \\ FRANCE Xing Liu \\ FRANCE Yoshihiro Okada \\ SPAIN Zuzana Palkova
}

SPAIN

AUSTRALIA

ARGENTINA

SPAIN

CANADA

SPAIN

SPAIN

ESTONIA

SPAIN

SWEDEN

ROMANIA

UNITED KINGDOM

FINLAND

LEBANON

SERBIA

UNITED ARAB EMIRATES

UNITED KINGDOM

SPAIN

MALAYSIA

SPAIN

CHILE

UNITED KINGDOM

INDONESIA

CZECH REPUBLIC

AUSTRIA

FRANCE

UNITED KINGDOM

UNITED KINGDOM

JAPAN

SPAIN

UNITED STATES

RUSSIAN FEDERATION

CROATIA

NEW ZEALAND

UNITED STATES

UNITED ARAB EMIRATES

CANADA

DENMARK

FRANCE

CANADA

JAPAN

SLOVAKIA 


\section{CONFERENCE SESSIONS}

\section{ORAL SESSIONS, 16th November 2017}

Design Thinking \& Creativity Teaching International Collaboration in Higher Education eAssessment

Accreditation and Quality in Education 21st Century Skills

Professional Development of Teachers (1)

Experiences and Trends in Health Sciences Education (1)

New Technologies in Foreign Language Learning

Flipped Learning

Study Abroad Experiences \& Exchange Programmes

e-Portfolios and Assessment Tools

Quality in Higher Education

Learning Management Systems

School Placement \& Practicum Experiences in Teacher Education

Soft Skills Development \& Experiential Learning

Experiences and Trends in Health Sciences Education (2)

Flipped and Blended Learning in Foreign Languages

e-Learning and Blended Learning Experiences

Early Childhood Experiences and Trends

Evaluation and Assessment (1)

University-Industry Collaboration

Technology in Teaching and Learning (2)

New Challenges for the Higher Education Area

Internship Programs and Experiences

Research and Innovation in Companies

New Experiences in Language Learning

Technology in Teaching and Learning (1)

Experiences in Primary and Secondary Education (1)

e-Content Management and Development

Research and Education Management

Digital Skills in Higher Education

New Experiences in Curriculum Design

Employability Issues and Challenges (1)

New Trends and Experiences in Business Education

Organizational and Financial Issues in Higher Education

POSTER SESSIONS, 16th November 2017

Emerging Technologies in Teaching and Learning

Innovations and Experiences in Education 


\section{ORAL SESSIONS, 17th November 2017}

Web 2.0 and Social Networking

Soft Skills in Higher Education

Pedagogical and Collaborative Methods

Public vs. Private Schools

Digital Literacy

Professional Development of Teachers (2)

Maths Teaching and Learning (1)

Experiences in Architecture Education

Special Education Experiences (1)

MOOCs: Massive Open Online Courses

Employability Issues and Challenges (2)

Collaborative and Project Based Learning Experiences

Educational Management and Leadership (1)

Student Support in Education

Professional Development of Teachers (3)

Maths Teaching and Learning (2)

Problem and Project Based Learning

Special Education Experiences (2)

Open Educational Resources

Entrepreneurship Education

Informal Learning Experiences

Ethical Issues in Education

Evaluation and Assessment (2)

ICT Skills and Competencies among Teachers

Experiences in Primary and Secondary Education (2)

Coding \& Programming Experiences

Special Education Professionals Development

Virtual Reality \& Simulation Labs

Service Learning \& Community Engagement

New Pedagogies and Experiences in Higher Education

Adult Education

Gamification

Pre-service and In-service Teacher Experiences (1)

STEM in Primary and Secondary Education

Pedagogical Innovations in Language Learning: EFL \& ESP

Inclusive Learning (1)

Learning Apps for Smartphones and Tablets

Gender Issues in Education

Tutoring \& Mentoring

Educational Management and Leadership (2)

Games for Learning

Pre-service and In-service Teacher Experiences (2)

STEM in Higher Education

Pedagogical Methods and Innovations

Inclusive Learning (2)

\section{POSTER SESSIONS, 17th November 2017}

Global Issues in Education and Research

Education Practice, Trends and Issues 


\section{VIRTUAL SESSIONS}

Academic Research Projects

Accreditation and Quality in Education

Adult education

Advanced classroom applications and technologies

Assessment of student learning

Barriers to Learning

Blended Learning and Flipped Classroom

Collaborative and Problem-based Learning

Cultural Diversity and Inclusive Learning

Curriculum Design

E-content Management and Development

e-learning experiences

e-Tutoring and e-Mentoring

Education practice trends and issues

Education, Research and Globalization

Educational/Serious Games and Software

Emerging Technologies in Education

Employability issues and trends

Experiences in Post-graduate education

Experiences in Primary and Secondary education

Experiences in Undergraduate education

Game-based learning and Gamification

Global Issues in Education and Research

ICT Skills

In-service training and Professional development of teachers

International Projects

Language Learning Innovations

Learning and Teaching Innovations

Learning Management Systems (LMS)

Learning space design: Next generation classroom

Life-long learning

Links between Education and Research

m-Learning: mobile applications and technologies

Massive Open Online Courses (MOOC)

New Challenges for the Higher Education Area

Online/Virtual Laboratories

Pedagogical Methods and Innovations

Pre-service teacher experiences

Research on Technology in Education

Special education

STEM Education Experiences

Student Support in Education

Teacher Training. ICT skills and training

Technology in Teaching and Learning

University-Industry Cooperation

Virtual and Augmented Reality

Virtual Learning Environments (VLE)

Vocational training

Web 2.0 and Social Networking

Women and minorities in science and technology 


\section{ABOUT ICERI2017 Proceedings}

\section{HTML Interface: Navigating with the Web browser}

This USB Flash drive includes all presented papers at ICERI2017 conference. It has been formatted similarly to the conference Web site in order to keep a familiar environment and to provide access to the papers trough your default Web browser (open the file named "ICERI2017_Proceedings.html").

An Author Index, a Session Index, and the Technical Program are included in HTML format to aid you in finding conference papers. Using these HTML files as a starting point, you can access other useful information related to the conference.

The links in the Session List jump to the corresponding location in the Technical Program. The links in the Technical Program and the Author Index open the selected paper in a new window. These links are located on the titles of the papers and the Technical Program or Author Index window remains open.

\section{Full Text Search: Searching ICERI2017 index file of cataloged PDFs}

If you have Adobe Acrobat Reader version 6 or later (www.adobe.com), you can perform a full-text search for terms found in ICERI2017 proceedings papers.

Important: To search the PDF index, you must open Acrobat as a stand-alone application, not within your web browser, i.e. you should open directly the file "ICERI2017_FrontMatter.pdf" with your Adobe Acrobat or Acrobat Reader application.

This PDF file is attached to an Adobe PDF index that allows text search in all PDF papers by using the Acrobat search tool (not the same as the find tool). The full-text index is an alphabetized list of all the words used in the collection of conference papers. Searching an index is much faster than searching all the text in the documents.

To search the ICERI2017 Proceedings index:

1. Open the Search PDF pane through the menu "Edit > Advanced Search" or click in the PDF bookmark titled "SEARCH PAPERS CONTENT".

2. The "ICERI2017_index.pdx" should be the currently selected index in the Search window (if the index is not listed, click Add, locate the index file .pdx, and then click Open).

3. Type the search text, click Search button, and then proceed with your query.

For Acrobat 9 and later:

1. In the "Edit" menu, choose "Search". You may receive a message from Acrobat asking if it is safe to load the Catalog Index. Click "Load".

2. A new window will appear with search options. Enter your search terms and proceed with your search as usual.

For Acrobat 8:

1. Open the Search window, type the words you want to find, and then click Use Advanced Search Options (near the bottom of the window).

2. For Look In, choose Select Index.

3. In the Index Selection dialog box, select an index, if the one you want to search is available, or click Add and then locate and select the index to be searched, and click Open. Repeat as needed until all the indexes you want to search are selected.

4. Click OK to close the Index Selection dialog box, and then choose Currently Selected Indexes on the Look In pop-up menu.

5. Proceed with your search as usual, selecting other options you want to apply, and click Search.

For Acrobat 7 and earlier:

1. In the "Edit" menu, choose "Full Text Search".

2. A new window will appear with search options. Enter your search terms and proceed with your search as usual. 


\title{
DRAWING AS LEARNING ENABLING META-LANGUAGE. USING SKETCH-NOTING IN THE FIELD OF EDUCATION
}

\author{
Letizia Bollini \\ Department of Psychology, University of Milano-Bicocca (ITALY)
}

\begin{abstract}
The use of information technologies is widely and massively impacting on the educational systems. From the adoption of the interactive tools such as the LIM as a support of teaching activities; to the substitutions of paper due to the introduction of tablet and publishing in the so-called 2.0 classes. All the aspects of the ICT have a strong impacting not only the instrumental environment of the school, higher education and universities, but also the way in which people learn and participate in the educational process.
\end{abstract}

An increasing number of studies compare how people take notes and how the modality effects on the mental model and information retention to understand the impact of ICT on the school system.

On one hand, using digital supports means to transcribe with a text editor on a computer what they're listening. On the other, taking notes traditionally means writing on paper.

These researchers are demonstrating extensive differences in the cognitive answers in favor of the analogical practices.

Studies show that the process of writing activates much more cognitive activities and produce a stronger organization of concepts and notions presented during the oral presentation.

Besides this traditional way, a new approach to note taking - based on the drawing techniques - is emerging and spreading. Visual facilitation and sketch noting use visual language to engage the brain in understanding, organizing and memorizing information and to experience a "meaningful learning" according to Ausubel theory.

The activity of drawing in itself connects both the analogical experience of linking the movement of the hand with the synthesis operated by the brain while listening or reading in a sort of translated choreography of our thoughts. Moreover, to draw means to convert a verbal input in a visual output, a textual or oral presentation in a visual representation.

The paper is aimed to map and discuss this drawing practices applied to the educational field as an alternative learning method, according to the different perspectives proposed by authors such as Brandy Agerback, Mike Rohde.

Keywords: Drawing as a learning enabling meta-language, Using sketch noting in the field of education, drawing, sketch-noting, visual language, visual design.

\section{DIGITAL TECHNOLOGIES IN EDUCATION}

The pervasive impact of ITC also in the education sector is deeply changing the way we teach and learn [1, 2]. In recent years the Italian government has started to promote the use of digital tools and artifacts both in the class and in the everyday activities. LIM, tablet and digital books are among the main innovation introduced in the secondary and high school. [3]

On one hand, the MIUR aims to let technologies be an inclusive factor in the state educational system on the other; it's trying to innovate the way people are trained [4].

Adobe, one of the leading companies in the field of graphics and interactive software is conducting extensive research to understand the needs, expectations, and attitude both of the so-called Gen Z. considered digital natives [5 Ferri] and of the teachers, still considered digital migrants [6].

The on-going research has been covering mainly English-speaking countries such as Australia, United Kingdom, the United States and Germany. From 2011 to 2017 Adobe has involved 2.500 students and 1.000 teachers to understand the connections between learning processes, technologies, and the professional future of Generation-Z [7]. 
Although the debate on generation segmentations is still open -Baby Boomers, Gen X, Gen Y, Millennials and so on [6] - Gen-Z is represented by pupils born between 1995 and 2010, 11-15 years old.

The research points out some emerging elements and some common thoughts. Enthusiasm and worrying for an uncertain future are the transversal feelings. But they express an overall balance between creativity and technology, both considered part of the present and the next challenge.

According to the survey, $93 \%$ of teachers are aware and worried of the perspective opened by digital: they are training for jobs that don't even still exist. By contrast, $76 \%$ of students believe that creativity will shape their hereafter careers.

Some trends seem to emerge in this transitional context. Technologies will be an enabling factor; works will imply both practical and creative activities, an ambivalent reaction both of optimism and concern for an uncertain social evolution, and, in the end, creativity as a key to succeeding.

\subsection{The elephant in the (class)room}

Although digital technologies are widely and pervasively reshaping the physical and cognitive educational environment, it is still not so clear how they are affecting the teaching/learning processes.

We are migrating from the traditional class to the 2.0 or 4.0 version in which chalkboards have been replaced by LIM, books by tablet and ebooks, encyclopedia by Wikipedia.

"The classroom will be no longer the place where notions are taught, but a place where participated work and discussions take place. A place to learn notions in a collaborative activities with peers and teachers" declares Ferri [3], one of the most well-known Italian experts of the relationship between students and technologies.

Furthermore, the law 133/2008 - promoted by the MIUR the Italian Ministry of School, University and Research [8] - explicitly requires to the educational system to encourage the adoption of hybrid books. That makes it compulsory - even if it's entirely unclear what hybrid means - that publishers have to distribute both the printed and digital version: online, ebook, apps whatever allows the book to be read on a digital device.

This introduces the first mutation in the teaching system, according to that many of the ready activities migrate from paper to bytes, from the book with a physical presence to an immaterial cognitive materiality. It is probably the first time in the human history - started with the invention of written notation that the reading support is separated from the content and the book becomes the reading machine, as underline by Gino Roncaglia [10] in the essay about the fourth revolution of the ebook.

Together with all the other ITC innovation, this fulfillment turns the way students produce their mental models of the written content they are supposed to study on [11, 12].

\subsection{Typing vs. writing in the learning process}

in those days, a world in which technology seems to be pervasive in every human activity, does still make sense to use one of the ancient human inventions such as the handwriting?

Not only the ITC revolution but also some national educational system are questioning if the writing does still make sense. Minna Harmanen, the president of the Finish National Board of Education, has recently declared that "Nowadays students do not have enough time to learn how to quickly hand write (in italic!); therefore we think it' not useful for them. Furthermore, it's not easy both for teacher and students to read it.

But the debate is becoming more and more animated. Pam Mueller - psychologist, and director of a research project conducted by the Princeton University - has an opposite position [14]. She held an experiment involving a students' class. The group was divided in two. The first was asked to use paper and pens, and the other one was asked to use the laptop, then they have to listen to a TEDTalk taking notes. At the end of the conference, the researchers questioned students on the topics discussed in the meeting.

Questions based solely on memory have almost the same results, but the ones focused on concepts and information connections the amanuensis had considerably higher scores. 
As stated by the author students using the computer were practically transcribing the lesson word for word. On the contrary, people taking handwritten notes, due to the slowness of the gesture, were more selective, including just crucial information, performing a better and more efficient learning strategy.

In a second experiment students using the computer were asked not to literally report the explained notions. Nevertheless, they find it was difficult to fulfill the task.

In a final assessment, Mueller asked both groups to study their notes to be examined in a week. She was expecting that the "digital" student would recover the gap thanks to the huge amount of data. Expectations have been disappointed: the researchers too were surprised that analogical people still perform better. Students using the computer were not able, from the beginning, to correctly and efficiently metabolize the notions.

That doesn't mean that there's a right answer, but people should be aware of the purpose they're taking notes, considering both the tool and the intent. Consequently, we should choose the way we take notes according to the use. If we need a deep learning strategy handwritten annotation, otherwise typing could be a right way to retain a waste amount of data. [15]

\subsection{Meaningful learning and conceptual maps}

The problem of how to perform an excellent way to learn and memorize information - that means to build a good knowledge and culture - was faced in the '60s by Asubel. In his studies on the psychology of education, he introduced a cognitive perspective, starting from a global approach [16] he then focused on the verbal side developing the concept of meaningful learning [17]. He then applies it also both to a learning method and a visualization model

Ausubel introduced the conceptual maps investigating the human learning and define them as a cognitive tool to and articulate content units; the maps also make evident the connections used to organize the units on hierarchy and pertinence criteria. Furthermore they make evident the key concepts and the prepositions linking the concepts; the maps use the visual communication channel to improve the learning and the retaining of the concepts. Verbal communication and the related verbal transcription are a sequential, linear process. The cognitive maps have a mesh-like and hierarchical structure, where the typical hierarchical structure of an hypertext is reproduced. The learning principle stated by Ausubel can be transferred also to the dynamical cognitive model for the learning the Website exploration: this is a continuous, dynamical and interactive process. as outlined in a previous search "The concept has been revised and developed by Novak and Gowin in the seventies; the proposed and developed the application in order to produce a graphical representation of the knowledge. As a geographical map allows to be directed inside an unknown land, in the same way a conceptual map allows the interpretation, the transmission and to revise the knowledge, the information and the data. The visualizations of the links between the different concepts makes evident the path of the possible reasoning." $[18,19]$ The cognitive maps then are: a graphical representation of concepts synthetically described (words, concepts) inside a geometrical form (a node) and linked together by lines showing the relations by means of words-links [20].

Cognitive maps allows the multimodal representation [21] of the information architecture highlighting the hierarchies, the nodes the physical (hypertextual) and conceptual connections between site contents. The interaction with the information is based on a generative dynamics of ryzomatic connections where the cognitive and perceptive richness Human User is evident, giving a more direct representation than the usual static structure tree [22].

Understanding is an active process in which we construct a model [23] of what we think and of the speaker's content: understanding means thus construct meaning by integrating new knowledge with those already in our acquired. According to Mayer [24] suggestions slides could be a valid support to oral presentation if they are a balanced mix between verbal and figural elements that convey and catch maintain the attention of the public/class if:

- words and images are presented and linked together;

- words and images are relevant and interrelated;

- words are presented orally and not only in the written form.

Moreover Clarks \& Lyons [25] have proposed a taxonomy of psychological functions that graphics and images play in the learning process: support the focus;activate prior knowledge; minimize the cognitive load; build mental models, help the transfer of learning, support motivation. 
"The maps indeed: produce a visual hierarchy simple and evident; allows the visualization of thematic nodes in the hypertext, and more mark up the logical and physical; connections, say the links; allows the visualization of many nesting levels of information at the same time in the same page; The solution based on the application of conceptual maps, as proposed by Novak and Gowin, overcomes the simple translation of contents to maps; a new interpretation of the method for setting up map is introduced, suggesting a critical approach to the structuring and to the navigation through knowledge." [26].

\section{VISUAL THINKING AND LEARNING}

The Ausubel model and the further improved by Novak and Gowin directly introduce to a spatial and visual approach to knowledge organization.

In recent time, Tony Buzan [27] has worked on the graphical side of the mind mapping proposing a standard approach and design pattern to use mapping as a conceptualization and cognitive tool. This tool has been confirmed as a learning method by Willis [28] in 2006 when Buzan launched his on software iMindMap [29] in the context of self-improvement educational courses.

If the digital technologies are becoming even more pervasive, on the other hand, we see a sort of reaction. Mental processes that need a slow time and a strong focus - opposed to multitasking and always on an experience of the IT devices - seem, then, to go back to the analogical environment in which representation skill, drawing abilities, and visual thinking are the discovery and learning drivers.

In this context, approaches that bring visual thinking and graphic language to the center are increasingly taking space. Dan Roam proposes a visual approach to problem-solving in his bestseller The Back of the Napkin: Solving Problems and Selling Ideas With Picture [30]. Brown claims the power of doodling as a way to free the create thought: colors pencils, pens, written patterns recurrent graphical mandala, coloring inside (or outside!) the outline of a printed figure methods to empower our creativity [31]. On the other side, Ellen Lupton proposes a structured use of the visual thinking supported by graphics methods to approach the analysis, ideation, conceptualization, and solution of a design problem [32].

The visual approach is an engaging way to understand, elaborate and connect concepts in a similar way to the meaningful learning activities explained by Ausubel. The challenge, then, is to bring these handwriting and drawing skills even to people who are not specifically trained in them [33]. The visual language, in fact, is and enabler both of knowledge and learning competences.

\subsection{Visual sketch noting}

A further step in this direction has been done by the visual practitioner's community. Personalities such as Agerbeck, Bird [34], Rodhe are actively raising and spreading a culture in which the graphic culture of colors, calligraphy, symbols, and signs is empowering people in understanding and remember notions and concepts. In particular, Brandy Agerbeck proposes the use of visual facilitation as a mediation tool, both in interpersonal or group dynamics and in complex communication systems. [35].

Mike Rodhe focus his research and dissemination work on sketch noting: it's not important how good you are in drawing, but how drawing can help you to visualize, remember and learn concepts, speeches and lessons. He helps people to learn how to use illustrative elements in note taking in a fast and effective way. The book Sketchnote Handbook: The Illustrated Guide to Visual Note Taking [36] is a practical and conceptual guide in practicing the visual and lettering language and how to use it as a powerful conceptual tool.

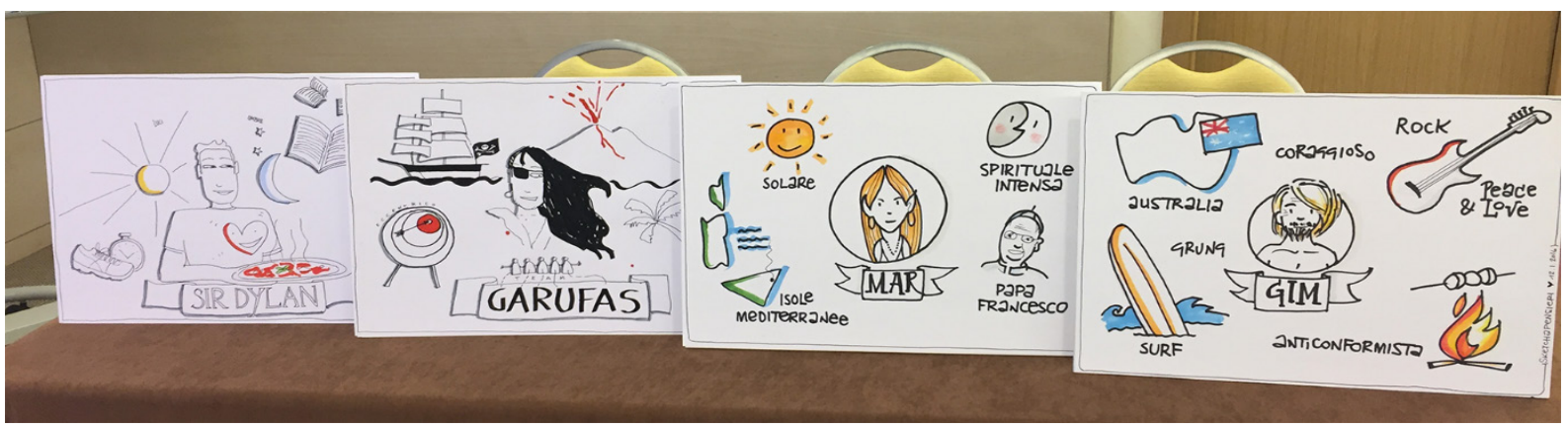

Figure 1. Visual recording: images by Erika Samsa \& Letizia Bollini 
This movement simplifies the visual representation culture to make it accessible to different public. The complexity of drawing language and techniques is reduced to basic and simplified geometrical shapes, arrows to connect concepts and frames to identify and divide issues and ideas. The initiative deserves attention and has the merit of opening the discipline also to those who are not specialists giving them an easy way to communicate.

This method not only activate a lot of connections among elements, as in the conceptual maps but uses a wider and richer graphical repertoire [37]. Colors, different lettering type and weight, a specific texture or conventional and hierarchical shapes, lines and link are a huge memorable glossary to express, categorize and, in the end, remember notions and data. Furthermore, drawing is both a physical and intellectual activity that implies a learning by doing experience [38]. If handwriting suggests a selection of information that already fixes concepts in the student memory, drawing create an additional effort to translate what's been heard in images or symbols.

\subsection{Drawing as a language}

"Drawing is at the same time an act of knowledge of the world around us and a creative one, embracing different project scales and design cultural branches. The visual-graphical level utilizes both the aspects" as underline during the last National congress of the Italian Drawing Union (Naples, 14-17 September 2017) "visual communication is, primarily, a form of representation. Therefore it shares the fundamental principles of the drawing language. As a prefigurative act of ideation, drawing moves its expressive repertoire draws on metrical, geometrical, proportional, spatial, and formal aspects of the whole composition as the first parameters to conceptualize and to communicate the message. [...] The visual language of graphic design, therefore, has its particular vocabulary. Its syntax and grammar are based on color theory, spatial and organizational canons, typography history and culture and the whole expressive range of the speech-figured rhetoric [39]. The visual communication is, moreover, a transversal language able to cross cultural boundaries and design scales to become an expressive field to unite hybrid and multidisciplinary scenarios." [40]
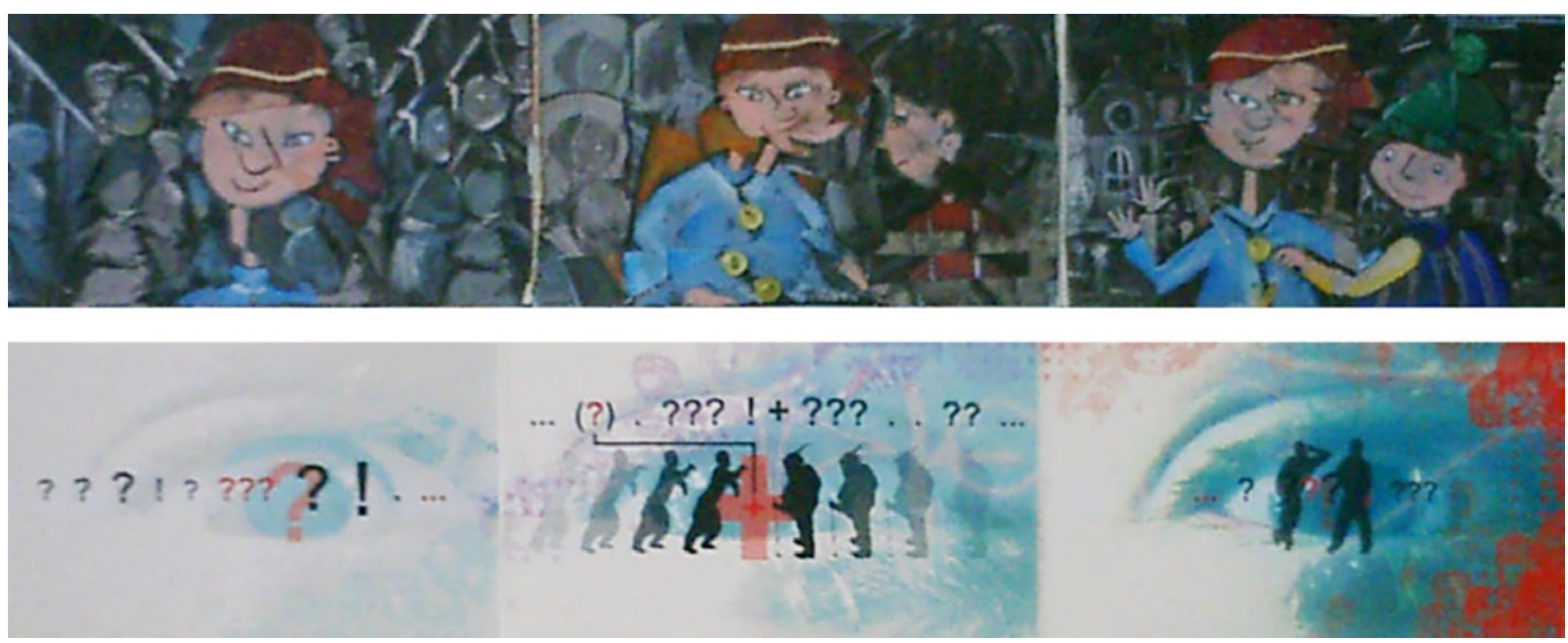

Figure 2. Style exercises: mages from the Graphic Design course, Psychosocial Communication Science Degree, University of Milano-Bicocca

\section{CONCLUSIONS}

Digital technologies are here to stay, and they are given a huge contribution to teaching methods and learning activities. Nevertheless, they fail when to try to substitute some basic cognitive processes such as understanding and information recording.

Analogical activities, handwriting above all, are helpful to synthesize, focalize and remember concepts and data. Besides, meaningful learning is based not only on a written note of ideas and connections organized in a spatial representation.

Drawing can foster this empowering role of visual in note-taking and learning activities, giving students a useful cognitive tool to understand and remember information. 
The next challenge in educational system is to give also to non-design course students [41] a basic and practical knowledge of the graphic language to be used in transversal learning activities

\section{REFERENCES}

[1] A. Calvani, Iperscola, Padova: Franco Muzzio,1994

[2] M. Russ, "Building a Learning Society", in Wired, no. 5/10, ottobre 1997. Retrieved from www.wired.com/wired/5.10/learning.html

[3] P. Ferri, Una nuova modalità didattica. La Scuola 2.0. Verso una didattica aumentata dalle tecnologie. Milano: Spaggiari, 2013

[4] L. Bollini, The challenge of a hybrid education between Computer Science and Design Competences in Italian University Courses and Degrees. In EDULearn16 Proceedings, pp. 6623-6632. Lisbona: IATED, 2016

[5] P. Ferri, Nativi digitali. Milano: Bruno Mondadori Editore, 2011

[6] L. Bollini, Learning by playing. A gamification approach to a language -learning digital tool. In ICERI2015 Proceedings, pp. 5271-5278. IATED, 2015

[7] Adobe, GEN Z in the Classroom: Creating the Future. Adobe education creativity study, 2017 Retrieved from http://www.adobeeducate.com/genz/

[8] L. Bollini, From paper to bytes. The transition to digital books in educational publishing: the Italian Experience. In Chova, LG; Martinez, AL; Torres, IC (Eds.) Proceedings of ICERI 2013 Conference, pp. 757-761. Seville: IATED, 2013

[9] L. Bollini, The fourth revolution the future of educational publishing in the transition to ebooks. In Chova, LG; Martinez, AL; Torres (Eds.) ICERI Proceedings 2014, p. 1982. Lisbona: IATED, 2014

[10] G. Roncaglia, La quarta rivoluzione. Sei lezioni sul futuro del libro. Bari: Laterza, 2010

[11] A. Calvani, Elementi di didattica. Roma: Carocci, 2000

[12] R. E: Mayer, Multimedia Learning. Cambridge: Cambridge University Press, 2001

[13] G. Donadio, La Finlandia abbandona il corsivo, non si insegnerà più. Ma i pareri si dividono, 2016. Retrieved from http://ischool.startupitalia.eu/education/55213-20160610-finlandiascrittura-corsivo

[14] P. Mueller \& D. M. Oppenheimer, "The Pen Is Mightier Than the Keyboard. Advantages of Longhand Over Laptop Note Taking" in Psychology Science, Vol 25, Issue 6, pp. 1159-1168, 2014. Retrieved from http://journals.sagepub.com/doi/abs/10.1177/0956797614524581

[15] CEST, "Prendere appunti fa bene alla memoria: secondo la scienza carta e penna aiutano a ricordare meglio dei portatili." in Huffington Post, 16/04/2015. Retrieved from http://www.huffingtonpost.it/2015/04/16/prendere-appuntimemoria_n_7078956.html?ncid=fcbklnkithpmg00000001

[16] D. P. Ausubel, Educational Psychology: a Cognitive View. New York: Holt, Rinehart, and Winston, 1968

[17] D. P. Ausubel, The Psychology of Meaningful Verbal Learning. Orlando, FL: Grune \& Stratton, 1963

[18] L. Bollini, G. Palma, Cognitive maps: new paradigms in information architecture and interface design for the web: the opsis identifier descriptive model for web information architecture based on cognitive maps: designing- $X$ a case study. In Novak (Ed.) Proceedings of the First International Conference on Concept Mapping. Pamplona, Spain, 2004

[19] L. Bollini, G. Palma, Web interface design based on cognitive maps: generative dynamics in information architecture. In 6th Generative Art Internatinal Conference, pp. 66-71, 2003

[20] J. D: Novak, D. B. Gowin, Learning How to Learn. Cambridge: Cambridge University Press, 1985

[21] L. Bollini, "Multimodalità vs. Multimedialità" in // Verri, no.16, pp. 144-148, 2001 
[22] L. Bollini, Registica Multimodale: il design dei New Media. Milano: CLUP, 2004

[23] T. Harley, Logica e conversazione. In P. Casalegno et Al. (Eds.) Filosofia del linguaggio. Milano: Raffaello Cortina, 2000

[24] R. E: Mayer, Multimedia Learning. Cambridge: Cambridge University Press, 2001

[25] R. C: Clark, and C. Lyon, Graphics for learning. San Francisco: Pfeiffer, 2004

[26] L. Bollini, Conceptual map based presentation in design education. In Chova, LG; Martinez, AL; Torres, IC (Eds.) Proceedings ICERI 2012 conference, pp. 3794-3796. Madrid: IATED, 2012

[27] T. Buzan, The Mind Map Book, 6 September 1993

[28] C. L. Willis, 'Mind maps as active learning tools', in Journal of computing sciences in colleges, Volume: 21 Issue: 4, 2006

[29] iMindMap software. Retrieved from https://imindmap.com/

[30] D. Roam, The Back of the Napkin: Solving Problems and Selling Ideas With Picture; London: Portfolio Penguin, London, 2013

[31] S. Brown, The Doodle Revolution: Unlock the Power to Think Differently. London: Portfolio Penguin, London, 2014

[32] E. Lupton, Graphic Design Thinking. New York: Princeton Architectural Press, 2011

[33] L. Bollini, Visual design for non-designers. A participatory experience based on web 2.0 tools in a multidisciplinary master degree programme. In Chova, LG; Martinez, AL; Torres, IC (Eds.) Proceedings Inted2012 conference, pp. 3157-3162. Valencia: IATED, 2012

[34] B. Agerbeck; K. Bird; S. Bradd; J. Shepherd, Drawn Together through Visual Practice. Kelvy Bird, 2016

[35] B. Agerbeck, The Graphic Facilitator's Guide: How to use your listening, thinking and drawing skills to make meaning. Retrieved from loosetooth.com, 2012

[36] M. Rohde, The Sketchnote Handbook: The Illustrated Guide to Visual Note Taking. San Francisco: Peachpit Press, 2012

[37] L. Bollini, \& M. Greco, Organizzare presentazioni efficaci. Milano: Hoepli, 2008

[38] L. Bollini, Learning by doing: A user centered approach to signage design. Milano bicocca a case study. In Chova, LG; Belenguer, DM; Torres, IC (Eds.) Proceedings Edulearn 2010 conference, pp. 3090-3097. Barcelona: IATED, 2010

[39] U. Eco and G. Fenocchio, Le ragioni della retorica. Modena: Mucchi Editore, 1986

[40] L. Bollini, II disegno come linguaggio. Esperienze didattiche di comunicazione visiva in contesti non progettuali / Drawing as a language. Teaching experiences in visual communication design for non-designers. In AA.VV. Territori e frontiere della Rappresentazione / Territories and frontiers of Representation, pp. 1203-1209. Roma: Gangemi Editore., 2017

[41] L. Bollini, The challenge of a hybrid education between Computer Science and Design Competences in Italian University Courses and Degrees, pp. 6623-6632. In EDULearn16 Proceedings. Lisbona: IATED, 2016 